\title{
PENGARUH IMPLEMENTASI KEBIJAKAN PENGAWASAN, KOMPETENSI APARATUR DAN BUDAYA ORGANISASI TERHADAP KINERJA PENGAWASAN BIDANG PENDIDIKAN DASAR DI KOTA DEPOK
}

\author{
Muhamad Nur ${ }^{1}$, Khasan Effendy ${ }^{2}$, M. Aries Djaenuri ${ }^{3}$, Sampara Lukman $^{4}$ \\ ${ }^{1,2,3,4}$ Institut Pemerintahan Dalam Negeri (IPDN) \\ Email: anuydy@gmail.com
}

\begin{abstract}
Abstrak
Penyelenggaraan pemerintahan diperlukan sebuah jalannya manajemen pemerintahan yang maksimal guna dicapainya penyelenggaraan pemerintahan yang baik (good governance) untuk mewujudkan kesejahteraan masyarakat dan merupakan tuntutan konstitusi pada Pembukaan Undang-Undang Dasar 1945 Alenia keempat. Pasal 31 Undang-Undang Dasar 1945 mengamatkan bahwa Pendidikan merupakan hak setiap warganegara dan pemerintah dan pemerintah daerah menjamin terselenggaranya sistem pendidikan nasional sesuai UndangUndang Nomor 20 Tahun 2003. Penelitian ini bertujuan untuk menguji dan menganalis pengaruh implementasi kebijakan pengawasan, kompetensi aparatur, dan budaya organisasi terhadap kinerja pengawasan bidang pendidikan dasar. Metode yang digunakan dalam penelitian ini adalah kuantitatif dengan kuesioner terbuka dan tertutup. Hasil penelitian ini menunjukkan bahwa ada hubungan yang positif dan signifikan antara implementasi kebijakan pengawasan, kompetensi aparatur dan budaya birokrasi terhadap kinerja pengawasan bidang pendidikan dasar baik secara parsial maupun secara simultan.
\end{abstract}

Kata Kunci: Pengawasan, Kompetensi Aparatur, Budaya Organiasi, Kinerja Pengawasan.

\begin{abstract}
The administration of government requires a way of maximizing government management in order to achieve good governance in order to realize the welfare of the people and constitute demands of the constitution at the Preamble of the fourth Alenia 1945 Constitution. Article 31 of the 1945 Constitution states that Education is the right of every citizen and the government and regional government guarantees the implementation of the national education system in accordance with Law Number 20 of 2003. This research aims to examine and analyze the effect of the implementation of supervisory policies, apparatus competencies, and culture organization of supervision performance in the field of basic education. The method used in this research is quantitative with open and closed questionnaires. The results of this study indicate that the causality relationship partially or simultaneously between the Implementation of Supervision Policy, Apparatus Competency and Bureaucratic Culture to the Supervision Performance of the Basic Education Sector is entirely positive and significant.
\end{abstract}

Keywords: Oversight, Apparatus Competency, Organizational Culture, Oversight Performance. 


\section{A. PENDAHULUAN}

Keberadaan sebuah negara pasti mempunyai tujuan bernegara dan berbangsa, tanpa terkecuali Negara Kesatuan Republik Indonesia (NKRI) juga mempunyai tujuan sebagaimana terdapat dalam Pembukaan Undang-Undang Dasar 1945 alinea keempat yaitu "Kemudian daripada itu untuk membentuk suatu pemerintah Negara Indonesia yang melindungi segenap bangsa Indonesia dan seluruh tumpah darah Indonesia dan untuk memajukan kesejahteraan umum, mencerdaskan kehidupan bangsa, dan ikut melaksanakan ketertiban dunia yang berdasarkan kemerdekaan, perdamaian abadi, dan keadilan sosial".

Dalam perspektif yuridis, tujuan NKRI terdapat dalam Undang-Undang Dasar 1945 pasal 1 ayat (1) yang berbunyi, "Negara Indonesia adalah negara kesatuan yang berbentuk republik". Sebagai negara republik, Indonesia memiliki banyak kewajiban kepada rakyatnya salah satunya untuk mencerdaskan kehidupan bangsa dan sesuai dengan Undang-Undang Dasar 1945 pasal 31 yang berbunyi, “(1) Setiap warga negara berhak mendapat pendidikan, (2) Setiap warga Negara wajib mengikuti pendidikan dasar dan pemerintah wajib membiayainya, (3) Pemerintah mengusahakan dan menyelenggarakan satu sistem pendidikan nasional yang meningkatkan keimanan dan ketaqwaan serta akhlak mulia dalam rangka mencerdaskan kehidupan bangsa yang diatur dengan undang-undang, (4) Negara memprioritaskan anggaran pendidikan sekurangkurangnya 20\% dari anggaran pendapatan dan belanja negara serta dari anggaran pendapatan dan belanja daerah untuk memenuhi kebutuhan penyelenggaraan pendidikan nasional, (5) Pemerintah memajukan ilmu pengetahuan dan teknologi dengan menjunjung tinggi nilai-nilai agama dan persatuan bangsa untuk kemajuan peradaban serta kesejahteraan umat manusia". Hal ini, dapat ditarik kesimpulan bahwa tujuan NKRI yaitu hak dan kewajiban pemerintah dan rakyat mengenai pendidikan serta kebudayaan.

Hak dan kewajiban tersebut dapat tercapai, maka diperlukan manajemen pemerintahan merupakan suatu proses kegiatan melakukan "tatakelola" atau pengelolaan pemerintahan oleh penguasa atau penyelenggara pemerintah dalam rangka mencapai tujuan yang telah ditentukan, yaitu meningkatkan kesejahteraan rakyat (Supriyanto, 2009:24). Pandangan manajemen pemerintah sebagai "suatu kegiatan atau usaha untuk mencapai tujuan negara dengan menggunakan berbagai sumber yang dikuasai oleh negara. Inti manajemen pemerintahan, 
terletak pada proses penggerakan untuk mencapai tujuan negara, dimana terkait erat dengan pendidikan".

Menurut Sedarmayanti (2003:76), good governance adalah suatu bentuk manajemen pembangunan, yang juga disebut administrasi pembangunan. Dengan demikian ia berpendapat bahwa pemerintahan berada pada posisi sentral (agent of chance) dari suatu masyarakat dalam suatu masyarakat berkembang. Dalam good governance tidak hanya pemerintahan, tetapi juga citizen, masyarakat yang dimaksud adalah masyarakat yang terorganisir, seperti LSM, asosiasiasosiasi kerja, bahkan paguyuban.

Sejalan dengan uraian tersebut, maka untuk mengaktualisasikannya terbitlah UndangUndang Nomor 23 Tahun 2014 tentang Pemerintahan Daerah, yang telah beberapa kali mengalami perubahan. Tujuannya Undang-Undang dimaksud adalah untuk mewujudkan kesejahteraan masyarakat daerah yang dilakukan dengan cara meningkatkan kualitas pelayanan, pemberdayaan masyarakat, dan pembangunan terbentuknya sarana dan prasarana di daerah yang layak. Disamping itu, juga untuk mewujudkan pengelolaan sumber daya alam secara efektif serta memberikan kesempatan bagi warga daerah untuk berpartisipasi di dalam penyelenggaraan pemerintahan. Dengan diterapkannya Undang-Undang tersebut, diharapkan kualitas dan daya saing daerah otonom semakin meningkat dan juga dapat berdampak pada kemajuan dan kesejahteraan masyarakatnya.

Dalam penyelenggaraan sistem pendidikan yang berlangsung dalam berbagai jenis dan jejang pendidikan merupakan bagian integral pembangunan nasional yang bertujuan membangun Manusia Indonesia Seutuhnya dan membangun Seluruh Masyarakat Indonesia. Penyelenggaraan sistem pendidikan menjadi tanggungjawab bersama antara pemerintah, masyarakat, dunia usaha, industri, dan keluarga. Karena itu, penyelenggaraan sistem pendidikan nasional perlu dioptimalisasikan agar tujuan pembangunan Manusia Indonesia Seutuhnya dan pembangunan seluruh Masyarakat Indonesia melalui pelaksanaan berbagai kebijakan dan kegiatan pendidikan dapat dicapai secara maksimal. Dengan tercapainya tujuan pembangunan Manusia Indonesia Seutuhnya dan pembangunan Seluruh Masyarakat Indonesia maka dengan sendirinya seluruh aspek kehidupan keluarga, masyarakat, bangsa dan negara menjadi lebih berkualitas, maju dan sejahtera. Selain itu, melalui pendidikan yang berkualitas, masyarakat Indonesia juga semakin 
mampu dalam menyikapi, mengatasi dan sekaligus dapat mengantisipasi dinamika perubahan sosial dan perkembangan masyarakat yang semakin mengglobal.

Tujuan pembangunan manusia Indonesia seutuhnya dapat tercapai apabila fungsi pendidikan dapat diselenggarakan secara efektif. Sementara itu tujuan pembangunan seluruh masyarakat Indonesia melalui penyelenggaraan sistem pendidikan dapat tercapai apabila penyelenggaraan sistem pendidikan dapat mencapai seluruh sasaran pendidikan di seluruh tanah air. Dengan efektivitas manajemen pendidikan yang tinggi setiap individu tentu tidak hanya memperoleh ilmu pengetahuan dan teknologi yang dibutuhkan untuk meningkatkan kompetensinya, tetapi memperoleh juga suasana pembelajaran yang memperkuat motivasi berprestasi. Karena itu, penyelenggaraan sistem manajemen pendidikan yang efektif secara fungsional meningkatkan kualitas sumber daya peserta didik dan efektif pula untuk meningkatkan kualitas lingkungan pendidikan. Dengan demikian, penyelenggaraan sistem manajemen pendidikan yang efektif merupakan faktor penting dalam penyelenggaraan system pendidikan nasional; dan sekaligus menjadi indikator kemampuan pihak pengelola pendidikan dalam melaksanakan fungsi pendidikan.

Guna mengoptimalisasikan penyelenggaraan sistem manajemen pendidikan yang semakin memperluas dan memperdalam penguasaan ilmu pengetahuan dan teknologi serta pembentukan sikap mental yang semakin berkualitas, maka penyelenggaraan sistem manajemen pendidikan di berbagai jenis dan jenjang pendidikan tentu tidak hanya membutuhkan dukungan berbagai sumber daya, namun juga membutuhkan kinerja kependidikan. Karena itu, para penyelenggara sistem manajemen pendidikan, terutama manajemen pendidikan dasar, tertantang untuk mampu meningkatkan profesionalitas dalam melaksanakan fungsi-fungsi manajemen pendidikan, agar penyelenggaraan pendidikan semakin efektif.

Penduduk Kota Depok berdasarkan proyeksi penduduk tahun 2016 sebanyak 2.179.813 jiwa. Jumlah tersebut terdiri atas 1.098 .473 jiwa penduduk laki-laki dan 1.081 .340 jiwa penduduk perempuan. Sex ratio (penduduk laki-laki dibandingkan penduduk perempuan) nya sebesar 102, yang artinya disetiap 100 orang perempuan terdapat 102 laki-laki. Dengan demikian, menujukkan antara jumlah penduduk laki-laki dan jumlah penduduk perempuan dapat dikatakan seimbang. 
Adapun jumlah PNS keseluruhan di Kota Depok sebanyak 7.146 orang yang terdiri dari Golongan I sebanyak 50 orang, Golongan II sebanyak 1.588 orang, Golongan III sebanyak 3.220 orang, dan Golongan IV sebanyak 2.288 orang (Sumber: Kota Depok Dalam Angka 2017). Adapun jumlah PNS yang terlibat dalam pengawasan bidang pendidikan dasar sebanyak 3.863 orang. Dengan demikian ratio PNS pengawasan bidang pendidikan dasar dibandingkan jumlah keseluruhan PNS di Kota Depok sebesar 54,05\%. Namun bila dilihat dari rasio berdasarkan pejabat (eselon) pengawasan bidang pendidikan dasar sebanyak 50 orang dengan rasio sebesar 6,37\% dari keseluruhan jumlah pejabat (eselon) di Kota Depok sebanyak 785 orang.

Berdasarkan uraian tersebut, maka kinerja pengawasan penyelenggaraan urusan pemerintahan daerah bidang pendidikan dasar dapat dikatakan berhasil, namun masih menyisakan permasalahan-permasalahan yang dapat dikatakan belum optimal. Hal ini dapat dikatakan kompleks dan menarik untuk diteliti.

\section{B. TINJAUAN PUSTAKA}

Hill and Hupe (2002:7) mengatakan bahwa: Implementation is the carrying out of basic policy decision, usually incorporated in a statute but which can also take the form of important executive orders or court decisions. Ideally, that decision identifies the problem(s) to be addressed, stipulates the objective(s) to be pursued, and in a variety of ways, "structures" the implementation process. The process normally runs through a number of stage begining with passage of basic statute, followed by the policy outputs (decisons) of the implementing agencies, the compliance of target groups with those decisions, the actual impact both intended and unintended of those outputs, the perceived impacts of agency decisions, and finally, important revisions (or attemted revisons) in the basic statute.

Implementasi kebijakan, menurut Hill and Hupe, suatu keputusan yang mengidentifikasi permasalahan untuk kemudian dicarikan berbagai cara penyelesaiannya dengan menunjukkan struktur pelaksanaan kebijakan yang bisa diikuti oleh para pelaksana kebijakan.

Budaya organisasi adalah keyakinan, norma dan etika kerja serta perilaku kerja yang berlangsung di setiap unit kerja birokrasi pemerintahan. Pemahaman budaya organisasi mencakup pada konsep dasar budaya organisasi. Budaya diciptakan agar masyarakat dalam kehidupan bermasyarakat tidak dapat terlepas dari ikatan budaya. Bagaimana ikatan budaya 
tersebut diciptakan oleh masyarakat yang bersangkutan, baik dalam keluarga, organisasi, bisnis maupun bangsa. Berkat adanya budaya dapat membedakan suatu kelompok masyarakat dengan kelompok yang lain. Perbedaan tersebut terlihat dari cara berinteraksi dan bertindak dalam penyelesaian suatu pekerjaan.

\section{METODE PENELITIAN}

Penelitian ini menggunakan penelitian kuantitatif. Pendekatan analisis kuantitatif dilakukan untuk mengetahui besarnya pengaruh implementasi kebijakan pengawasan, kompetensi aparatur, dan budaya organisasi terhadap kinerja pengawasan Bidang Pendidikan Dasar. Analisis kuantitatif tersebut dilakukan dengan Metode Analisis SEM (Structural Equation Models Analysis). Kemudian, hasil analisis SEM diperoleh Comfirmatory Factor Analysis (CFA). Hasil CFA dipandang sebagai temuan penelitian, dan selanjutnya berdasarkan hasil CFA dilakukan analisis untuk mendapat konsep baru (Wijanto, 2008).

\section{HASIL DAN PEMBAHASAN}

Hasil analisis SEM dengan kuesioner tertutup dibedakan menjadi 3 yaitu Rekapitulasi Hasil Uji Kecocokan Keseluruhan Model (Overall Model Fit), Hasil Pengukuran Model Struktural (Structural Model Fit) dan Pengujian Hipotesis. Hasil Uji Kecocokan Keseluruhan Model yang berfungsi untuk menunjukkan derajat kecocokan antara data dengan model. Hasil Pengukuran Model Struktural dan Pengujian Hipotesis yang berfungsi untuk menunjukkan signifikansi dan besarnya pengaruh variabel-variabel laten eksogen terhadap variabel laten endogen. Adapun hasil analisis SEM tersebut adalah sebagai berikut:

\section{Rekapitulasi Hasil Uji Kecocokan Keseluruhan Model}

Penelitian ini, peneliti menggunakan Structural Equation Modeling (SEM) dengan program LISREL, dimana metode ini digunakan untuk menguji secara bersama-sama model dari variabel independen dan variabel dependen. Variabel independen meliputi Impelementasi Kebijakan Pengawasan, Kompetensi Aparatur, Budaya Organisasi, dan Gabungan Varibel. Gabungan variabel adalah variabel yang dimensi-dimensinya diperoleh dari dimensi-dimensi Implementasi Kebijakan Pengawasan, Kompetensi Aparatur, dan Budaya organisasi. Variabel 
Dependen yaitu Kinerja Pengawasan Bidang Pendidikan Dasar. Hal ini telah dilakukan pengujian validitas dan reliabilitas dengan model Confirmatory Factor Analysis (CFA). Tahap selanjutnya adalah menganalisis hasil uji kecocokan data dengan model secara keseluruhan dengan menggunakan LISREL yang disebut Derajat Kecocokan atau Goodness of Fit (GOF).

Hasil uji kecocokan keseluruhan model pengaruh Implementasi Kebijakan Pengawasan terhadap Kinerja Pengawasan Bidang Pendidikan Dasar dapat disimpulkan dengan kategori yang menunjukkan kecocokan yang baik (good fit), karena hasil estimasi untuk NFI, NNFI, CFI, IFI, dan RFI lebih besar dari tingkat kecocokan yang disyaratkan sebagaimana pada tabel 4.8 (Hair et al. dalam Wijanto, 2008).

Kecocokan ini bermakna, bahwa teori implementasi kebijakan publik menurut Edward III (1980: 9-12) yang dijadikan landasan teoritik penyusunan konsep operasional variabel dan penyusunan instrumen penelitian dapat dinyatakan cocok untuk mengungkap dan membahas pengaruh Implementasi Kebijakan Pengawasan terhadap Kinerja Pengawasan Bidang Pendidikan Dasar yang diselenggarakan oleh Inspektorat Kota Depok dan Dinas Pendidikan Kota Depok. Kemudian kecocokan tersebut terpola berdasarkan rujukan teori implementasi kebijakan publik menurut Edward III (1980: 9-12) yang disusun dalam bentuk definisi konseptual, dimensi kajian, dan indikator-indikator pada variabel laten Implementasi kebijakan Pengawasan serta dikembangkan menurut karakteristik masalah yang dijadikan obyek penelitian yaitu Kinerja Pengawasan Bidang Pendidikan Dasar yang diselenggarakan oleh Inspektorat Kota Depok dan Dinas Pendidikan Kota Depok.

Sedangkan Hasil uji kecocokan keseluruhan model pengaruh Kompetensi Aparatur terhadap Kinerja Pengawasan Bidang Pendidikan Dasar dapat disimpulkan dengan kategori yang menunjukkan kecocokan yang baik (good fit), karena hasil estimasi untuk NFI, NNFI, CFI, IFI, dan RFI lebih besar dari tingkat kecocokan yang disyaratkan sebagaimana pada tabel 4.9 (Hair $e t$ al. dalam Wijanto, 2008). Kecocokan ini bermakna, bahwa teori Kompetensi menurut Spencer and Sepencer (1993:11) yang dijadikan landasan teoritik penyusunan konsep operasional variabel dan penyusunan instrumen penelitian dapat dinyatakan cocok untuk mengungkap dan membahas pengaruh Kompetensi Aparatur terhadap Kinerja Pengawasan Bidang Pendidikan Dasar yang diselenggarakan oleh Inspektorat Kota Depok dan Dinas Pendidikan Kota Depok. 


\section{Hasil Pengujian Model Struktural dan Pengujian Hipotesis}

Berangkat dari hasil persamaan pengukuran variabel laten eksogen Implementasi Kebijakan Pengawasan, Kompetensi Aparatur, dan Budaya Organisasi dan variabel laten endogen Kinerja Pengawasan Bidang Pendidikan Dasar, selanjutnya dilakukan pengukuran persamaan struktural yang menunjukkan besarnya pengaruh variabel laten eksogen terhadap variabel laten endogen. Hasil pengukuran model struktural dan pengujian hipotesis yang merujuk pada 4 (empat) pernyataan hipotesis yang diajukan dalam penelitian ini adalah sebagai berikut :

a. Berdasarkan hasil pengujian hipotesis terlihat bahwa nilai tvalue sebesar 14,96 (dengan tingkat keyakinan 95\%) dan cut of value yang disyaratkan sebesar 1,96 (nilai t-value 1,96), maka menunjukkan bahwa Implementasi Kebijakan Pengawasan berpengaruh positif dan signifikan terhadap Kinerja Pengawasan Bidang Pendidikan Dasar. Besarnya pengaruh tersebut dilihat dari hasil pengukuran koefisien jalur (path) sebesar 0,94. Besarnya path menunjukkan bahwa koefisien jalur dapat dikatakan sangat kuat (sangat signifikan) adanya pengaruh antara Implementasi Kebijakan Pengawasan dengan Kinerja Pengawasan Bidang Pendidikan Dasar yang diselenggarakan oleh Inspektorat Kota Depok dan Dinas Pendidikan Kota Depok yang terjalin suatu hubungan kausalitas yang bermakna.

b. Berdasarkan hasil pengujian hipotesis terlihat dari penyajian path diagram nilai $t$-value sebesar 14,14 (tingkat keyakinan 95\%) dan cut of value yang diisyaratkan sebesar 1,96 (nilai $t$-value 1,96) menunjukkan bahwa Kompetensi Aparatur berpengaruh positif dan signifikan terhadap Kinerja Pengawasan Bidang Pendidikan Dasar. Besarnya pengaruh dari hasil pengukuran koefisien jalur yang menunjukkan sebesar 0,94 lebih besar dari 0,50 dapat dinyatakan hubungan kausalitas signifikan. Adanya pengaruh tersebut menunjukkan bahwa antara Kompetensi Aparatur dengan Kinerja Pengawasan Bidang Pendidikan Dasar yang diselenggarakan oleh Inspektorat Kota Depok dan Dinas Pendidikan Kota Depok terjalin suatu hubungan kausalitas yang bermakna.

c. Hasil pengujian hipotesis terlihat bahwa Nilai t-value sebesar 14,16 (tingkat keyakinan 95\%) dan cut of value yang disyaratkan sebesar 1,96 (nilai t-value 1,96), maka menunjukkan bahwa Budaya Organisasi berpengaruh positif dan signifikan terhadap Kinerja Pengawasan Bidang Pendidikan Dasar. Besarnya pengaruh tersebut juga dilihat 
dari hasil pengukuran koefisien jalur (path) sebesar 0,94 lebih besar dari 0,50 yang dipersyaratkan dan dapat dinyatakan bahwa hubungan keterpengaruhan sangat kuat. Adanya pengaruh tersebut menunjukkan bahwa antara Budaya Organisasi dengan Kinerja Pengawasan Bidang Pendidikan Dasar yang diselenggarakan oleh Inspektorat Kota Depok dan Dinas Pendidikan Kota Depok terjalin suatu hubungan kausalitas yang bermakna.

d. Hasil model pengukuran pada Tabel 4.17 menunjukkan bahwa nilai loading factor masing-masing memiliki korelasi yang kuat terhadap konstruk variabel lateh eksogen Budaya Organisasi. Mengacu pada pemeriksaan secara keseluruhan bobot faktor Innovation and Risk Taking, faktor Attention to Detail, faktor Outcome Orientation, faktor People Orientation, faktor Team Orientation, faktor Aggressiveness, dan faktor Stability terungkap bahwa semua faktor telah memberi nilai loading factor yang signifikan pada variabel laten eksogen Budaya Organisasi. Signifikansi ini diketahui dari nilai $t$-Value lebih besar dari Cut off Value $(1,96)$ dan nilai loading factor lebih besar dari yang dipersyaratkan yakni 0,50. Dengan demikian faktor-faktor yang tercakup pada variabel laten eksogen Budaya Organisasi mempunyai hubungan yang signifikan secara statistik terhadap konstruknya dan variabel-variabel manifes yang membentuk bobot masing-masing faktor dapat dinyatakan valid.

Dengan demikian Attention to Detail sebagai faktor Budaya Organisasi dalam penyelenggaraan Kinerja Pengawasan Bidang Pendidikan Dasar menjadi penting, karena Attention to Detail sebagai faktor Budaya Organisasi merupakan salah satu faktor yang turut menentukan Kinerja Pengawasan Bidang Pendidikan Dasar yang diselenggarakan oleh Inspektorat Kota Depok dan Dinas Pendidikan Kota Depok. Faktor Attention to Detail sebagai faktor Budaya Organisasi ini meliputi indikator-indikator, berikut: (1) Kecermatan dalam pengawasan, (2) Ketepatan dalam pengawasan, dan (3) Kehati-hatian Pengawasan.

Berdasarkan hasil pengukuran model struktural dan pengujian hipotesis, sebagaimana pada Gambar 4.5 menunjukkan bahwa ketujuh dimensi kajian Budaya Organisasi yang mencakup (1) Dimensi Innovation and risk taking, (2) Dimensi Attention to detail, (3) Dimensi Outcome orientation, (4) Dimensi People orientation, (5) Dimensi Team orientation, (6) Dimensi Aggressiveness, dan (7) Dimensi Stability berkontribusi dalam proses pembentukan 
besarnya pengaruh terhadap Kinerja Pengawasan Bidang Pendidikan Dasar yang diselenggarakan oleh Inspektorat Kota Depok dan Dinas Pendidikan Kota Depok. Besarnya kontribusi dalam proses terbentuknya pengaruh pada Kinerja Pengawasan Bidang Pendidikan Dasar ditunjukkan oleh tiga dimensi variabel Kinerja Pengawasan Bidang Pendidikan Dasar, yaitu: (1) dimensi penetapan standar kinerja pengawasan pendidikan dasar, (2) dimensi penilaian kinerja aktual pengawasan pendidikan dasar, dan (3) dimensi umpan balik kinerja pengawasan pendidikandasar.

\section{Analisis Kuantitatif dengan Qualitative Data Analisys (QDA)}

Hasil analisis kuantitatif dengan menggunakan kuesioner terbuka dengan menggunakan software Qualitatif Data Analisys Miner Lite 2.0.6. Teknik-teknik analisis data kuesioner terbuka berbeda dengan analisis data kuantitatif dengan kuesioner tertutup. Teknik analisis kuantitatif ini dapat dibantu program aplikasi. Aplikasi hanya merupakan alat bantu (tools), keberhasisilan analisis kuantatif kuesioner terbuka (kuantitatif) tetap bergantung kepada kemampuan pikir tajam dan kritis penulis sendiri. Langkah-langkah yang dilakukan peneliti dalam analisis kuantitatif dengan kuesioner terbuka terlebih dahulu melakukan pengkodean (coding), yaitu proses menyisir transkrip yang ditulis pada kuesioner terbuka, sketsa, foto, atau video untuk mencari topik, tema, ide, konsep, kategori, kata-kata kunci, atau apapun yang bermakna di dalamnya dan kemudian menandainya. Kerangka pengkodean (developing a coding scheme) disesuaikan dengan dimensi dan indikator pada analisis kuantitatif kuesioner tertutup. Namun, apabila dalam penelitian digunakan kuesioner terbuka dan ditemukan transkrip dari kuesioner terbuka, sketsa, foto, atau video yang dianalisis belum ada pengkodeannya, maka dibuat pengkodean Baru (New coding).

Dengan demikian, perlu melakukan revisi terhadap skema pengkodean awal (Revising the coding scheme). Analisis tersebut diperlukan ketajaman berpikir sebagai instrumen penelitian, sehingga revisi dalam pelaksanaan penelitian merupakan suatu keniscayaan. Seiring penambahan New Coding yang mengkibatkana kerangka pengkodean yang semakin kompleks. Dengan demikian perlu disederhanakan (Simplifying the coding scheme), antara lain dengan menggabungkan kode yang mempunyai kesamaan menjadi satu kode baru yang lebih umum disebutn dengan menambahkan kode baru (Developing new codes). 


\section{E. KESIMPULAN}

Bertolak dari hasil penelitian dapat disimpulkan bahwa ada pengaruh yang positif dan signifikan antara implementasi kebijakan pengawasan, kompetensi aparatur, dan budaya organisasi terhadap kinerja pengawasan Bidang Pendidikan Dasar di Kota Depok baik secara parsial maupun secara simultan.

\section{DAFTAR PUSTAKA}

Ainsworth, M, Smith, S., \& Millership, A. (2002). Managing Performance People. Jakarta: PT. Bhuana Ilmu Populer.

Apter, D. (1965). Comperative Politics. New York: The Free Press.

Basuki, J. (2007). Budaya Organisasi-Konsep dan Terapan. Jakarta: Yayasan Pembina Manajemen.

BPS. (2017). Kota Depok Dalam Angka Tahun 2017

LAN RI. (1997). Sistim Administrasi Negara Republik Indonesia. Jakarta: PT. Toko Gunung Agung.

Ndraha, T. (2011). Kybernology (Ilmu Pemerintahan Baru). Jakarta: Rineka Cipta.

Ndraha, T. (1997). Budaya Pemerintahan dan Dampaknya Terhadap Pelayanan Masyarakat. Jurnal Ilmu Pemerintahan.

Sedarmayanti. (2003). Good Governance (Kepemerintahan Yang Baik) Dalam Rangka Otonomi Daerah. Bandung: Mandar Maju.

Spencer, L. M., \& Spencer, P. S. M. (1993). Competence at Work models for superior performance. John Wiley \& Sons.

Subagio, U., Miyasto, M., \& Idris, I. (2014). Analisis Pengaruh Budaya Organisasi, Kompetensi dan Komitmen Organisasi Terhadap Kerja Pegawai Yang Dimediasi Oleh Motivasi Kerja (Studi Perwakilan Bpkp Provinsi Jawa Tengah). Jurnal Bisnis Strategi, 23(1), 138-148.

Terry, G. R. (1979). Principles of Management. Bandung: Alumni.

Waluyo, M. (2005). Pengaruh Harga Rokok, Budaya Organisasi, Orientasi Pasar, Promosi Terhadap Kinerja Pemasaran dan Keunggulan Bersaing Berkelanjutan pada Perusahaan Rokok Kecil Jenis Sigaret Kretek Tangan di Jawa Timur (Doctoral dissertation, Universitas Airlangga). 